\title{
Current dietary supplement use of Australian military veterans of Middle East operations
}

\author{
Jolieke $C$ van der Pols ${ }^{1,2, *}$, Jeeva Kanesarajah ${ }^{1}$, Alison Bell ${ }^{3}$ and Chi-Wai Lui ${ }^{1}$ \\ ${ }^{1}$ The University of Queensland, School of Public Health, Herston, QLD 4006, Australia: ${ }^{2}$ Queensland University of \\ Technology, School of Exercise and Nutrition Sciences, Kelvin Grove, QLD, Australia: ${ }^{3}$ Recover Injury Research \\ Centre, Faculty of Health and Behavioural Sciences, The University of Queensland, Herston, QLD, Australia
}

Submitted 18 July 2016: Final revision received 26 May 2017: Accepted 19 June 2017: First published online 15 August 2017

\begin{abstract}
Objective: To assess patterns and levels of dietary supplement use among Australian Defence Forces, previously deployed to the Middle East Area of Operations.

Design: A cross-sectional study. Participants of a large survey self-completed questions about dietary supplement use, health status, personal and job-related characteristics, and lifestyle factors. Frequency of current use of supplements was assessed in three categories (bodybuilding, energy and weight loss).

Setting: Middle East Area of Operations post-deployment health survey.

Subjects: Current and ex-serving Australian Defence Force personnel ( $n$ 14032) who deployed to the Middle East between 2001 and 2009.

Results: Bodybuilding supplements were used by $17.5 \%$ of participants, energy supplements by $24.5 \%$ and weight-loss supplements by $7.6 \%$. Overall, $32.3 \%$ of participants used any of these supplements. Bodybuilding and energy supplements were more often used by men, younger persons and those in the Army, while weight-loss supplements were more commonly used by women and Navy personnel. Supplements in all three categories were more commonly used by persons in lower ranks, active service and combat roles. Users of bodybuilding supplements had healthier lifestyles and better health status, while users of energy and weight-loss supplements had less healthy lifestyles and poorer mental and physical health status. Overall, $11.7 \%$ of participants used supplements containing caffeine and $3.6 \%$ used a creatine-containing product.

Conclusions: Use of dietary supplements among Australian Defence Force personnel is common, and patterned by lifestyle factors and health status.
\end{abstract}

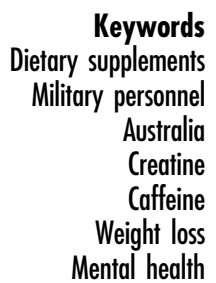

Use of dietary supplements is common in many Western countries including Australia, where national data indicate that almost a third of adults use these products ${ }^{(1)}$. However, the efficacy and safety of dietary supplements have long been debated ${ }^{(2)}$. Carbohydrate and/or protein drinks can offer benefits during an extended period of intensive exercise ${ }^{(3,4)}$, or iron and calcium supplements can be beneficial for persons with low dietary intakes of these nutrients ${ }^{(5)}$. Due to the high physical demands commonly experienced by military personnel, they choose to use dietary supplements to improve energy levels, performance, muscle strength and endurance, and to promote general health ${ }^{(6)}$. Overweight and obesity are also increasingly affecting military populations ${ }^{(7,8)}$, which may lead to use of supplements marketed for weight loss in this population group, to help them to meet the fitness standards required for employment in military services.
However, many of the available supplements offer no health benefits ${ }^{(9)}$ and some may cause harm when multiple supplements are used, when intake exceeds the recommended $\operatorname{dose}^{(10)}$ or when their use causes a person's total intake to exceed recommended levels. For example, caffeine and creatine supplements can have ergogenic and performance-enhancing effects ${ }^{(11,12)}$, but caffeine-containing supplements add to the caffeine intake from drinks and caffeine intake levels in US military personnel have been reported to be high ${ }^{(13)}$. Some studies have shown possible risks associated with high caffeine intake, including a negative effect on sleep patterns ${ }^{(14)}$, although the effects of high caffeine intake on sleep quality in a combat environment have not been established definitively ${ }^{(15)}$. Certain weight-loss related supplements have been associated with gastrointestinal distress and nervousness ${ }^{(16,17)}$. 
Current evidence indicates that use of dietary supplements by military personnel is higher than that in the general population in Western countries. More than $50 \%$ of US soldiers ${ }^{(6)}$ and almost $40 \%$ of British soldiers in training $^{(18)}$ reported use of dietary supplements, with many using multiple products; and use is higher in army personnel serving in conflict zones ${ }^{(19,20)}$. Products targeting muscle strength, muscle mass and endurance are favoured by British and US military personnel ${ }^{(6,19,21-23)}$, and weight-loss supplements are also commonly used by US military personnel ${ }^{(24)}$.

Most of the evidence on use of dietary supplements by military personnel comes from data collected on US and British military personnel, but evidence for Australian military personnel, who can take typical multivitamin preparations approved by the Australian Therapeutic Goods Administration at recommended doses without prior approval, is lacking. We therefore investigated levels and patterns of use of dietary supplements by Australian military personnel, particularly those who have experienced deployment to conflict zones. We studied the characteristics of dietary supplement users by assessing general demographic factors, service and lifestyle factors, and mental and physical health status.

\section{Methods}

\section{Study design and participants}

We analysed data from a large cross-sectional survey of current and ex-serving Australian Defence Force (ADF) members who deployed to the Middle East Area of Operations (MEAO) between 1 October 2001 and 31 December $2009^{(25)}$. This survey included MEAO veterans deployed to Iraq or areas supporting operations in Iraq (including ships in the Persian Gulf), those deployed to Afghanistan or areas supporting operations in Afghanistan, and those attached to foreign militaries or the UN in the above areas. A small proportion (6\%) of participants had left the ADF since serving in the Middle East. These exserving personnel were included in the present study to capture current supplement use of all persons who had served in the Middle East previously and improve representation of all those who served.

\section{Data collection}

Data were collected in 2010 and 2011 through online surveys or hard copy questionnaires that were sent to all eligible current and former ADF members for completion. Participation was voluntary and anonymous. Full details on the participant recruitment, response rates, survey design and methodology are documented elsewhere ${ }^{(25)}$. In brief, all participants completed a questionnaire that asked about demographic characteristics, their role during the most recent deployment, current health status, lifestyle behaviours and health symptoms. Participants were asked the following questions in relation to their supplement use: 'How often do you currently take any of the following supplements? Body building supplements (such as amino acids, weight gain products, creatine etc.); Energy supplements (such as energy drinks, pills, or energy enhancing herbs); Weight loss supplements?', with response options of 'never', 'less than once a month', 'monthly', 'weekly' and 'daily or almost daily'. The respondent was then asked to record the name (generic or brand name) of the supplement they used, for each of the three categories.

The supplement brand name and type listed by the participant were entered into an Internet search engine to verify the product was a dietary supplement and to obtain product information. Products in each of the three supplement categories (bodybuilding, energy and weight loss) were coded into sub-categories based on the most prominent type of ingredients, including protein and amino acids, multivitamins and herbs, carbohydrates and sugars, stimulants, and creatine monohydrate. We further identified which products contained either creatine or caffeine in each sub-category, given the concern about possible sideeffects associated with these ingredients. Manual coding of the data was undertaken by one author and incongruities were resolved through discussion with all authors.

Lifetime smoking history was self-reported in three categories (current smoker; ex-smoker; never smoker) and caffeine use was ascertained as the reported average daily consumption of caffeine-containing beverages (250-375 ml) grouped into four categories (none; 1-2 per day; 3-5 per day; 6 or more per day). Participants were asked to report whether they experienced selected health symptoms (e.g. sleeping difficulties, headaches, vomiting) in the past month. The Short Form-12 Survey (SF-12) ${ }^{(26)}$ was completed as part of the study questionnaire, and summary component scores for physical and mental health calculated using standardised methodology. Major depressive syndrome was derived using the Patient Health Questionnaire (PHQ-9) Depression module, which evaluates the frequency of nine DSM-IV (the Diagnostic and Statistical Manual of Mental Disorders, 4th edition) criteria for major depression syndrome in the last two weeks ${ }^{(27)}$. Major depression was considered present if five or more of the nine depressive symptoms were reported more than half the time in the past two weeks, and if one of the symptoms reported was depressed mood or anhedonia.

Ethical approval for the present study was obtained from the Australian Department of Defence (protocol number LREP 14-010) and The University of Queensland (protocol number 2009001441) ethics committees. Participants of the MEAO Survey provided consent in writing or electronically, and all aspects of this research complied with the Declaration of Helsinki.

\section{Statistical analysis}

We assessed the proportion of respondents who reported using supplements in each of the three supplement 
categories by subgroups of general demographic characteristics, service and lifestyle characteristics, and the presence or absence in the past month of a number of specified health symptoms. Differences between subgroups were ascertained by using binary logistic regression analysis to calculate OR and 95\% CI. Univariate comparisons were followed by multivariable-adjusted models with adjustment for possible confounding by all other demographic, service and lifestyle factors considered (only factors with evidence of confounding, based on evidence from the literature and changes in the risk estimate when the covariate was included, were retained in the model). Physical and mental health scores from the SF-12 instrument were continuous variables and comparisons between subgroups carried out using multivariable linear regression weighted for non-response. The total number of health symptoms was modelled as a count variable, using the negative binomial model with robust SE. All data were weighted for non-response, based on the response rates in the three service groups (Navy, Army, Air Force), four service status groups (active regulars, active reserves, inactive reserve, ex-serving), three rank categories (commissioned officers, non-commissioned officers, other ranks), and among males and females. This resulted in seventy-two strata and weights calculated were the inverse of the response rate in each stratum. Count data (number of participants) in subgroups of supplement use are presented as unweighted data, but all summary statistics such as percentages, means and OR were based on weighted data. All analyses were carried out using the statistical software package SAS version 9.3.

\section{Results}

A total of 26239 eligible ADF members were invited to participate and 14032 (53\%) responded to the survey. Most of the respondents were male (88.9\%), mean age was 37 years (range 18-68 years), and 49.3\% were Army, 23.6\% Navy and 27.1\% Air Force personnel. Alcohol use was common ( $48.3 \%$ consumed 1-2 alcoholic drinks/d, $33.9 \%$ drank 3-5 alcoholic drinks/d and 6.1\% drank $\geq 6$ alcoholic drinks/d), and $28.2 \%$ were current smokers. A small proportion $(6 \cdot 0 \%)$ of the participants had left the ADF since serving in the Middle East. Mean age of ex-serving participants $(36.4$ years) was similar to that of active regular personnel ( 35.8 years), while the average age of active reserve and inactive reserve personnel was slightly higher (39.7 and 37.2 years, respectively).

Analysis of non-response was reported previously ${ }^{(25)}$ and showed that response rates were higher among females (59\% of females responded $v .52 \%$ of males), older persons $(67 \%$ of those aged $\geq 45$ years responded $v$. $39 \%$ of those aged $18-25$ years old), personnel of the Air Force $(60 \%$ responded $v$. $50 \%$ of those in the Navy and $51 \%$ of those in the Army), those ranked as officer
( $63 \%$ of officers responded $v .35 \%$ of those in other ranks) and personnel actively serving in the military $(58 \%$ of those in active employment responded $v$. 32\% of ex-serving personnel).

Use of dietary supplements was common among the study participants, with $21.5 \%$ of respondents using a dietary supplement in any of the three categories once weekly or more often. Overall, $32.3 \%$ of participants used any of the three types of supplement investigated (at any frequency of use), with bodybuilding supplements (17.5\%) and energy supplements (24.5\%) used more often than weight-loss supplements $(7 \cdot 6 \%) ; 11.6 \%$ of participants used supplements in more than one category. A large proportion of users of bodybuilding supplements used these daily (47.9\%), while $21.7 \%$ used these weekly and $30.4 \%$ monthly. Energy supplements were used daily by $28.8 \%$ of users of these supplements, weekly by $27 \cdot 1 \%$ and monthly by $44.2 \%$. Weight-loss supplements were used daily by $42.5 \%$ of respondents who used such supplements, weekly by $15.5 \%$ and monthly by $42.0 \%$. The number of different bodybuilding supplements used per person ranged from 1 to 5 different products (average $1 \cdot 1$ products per person), and this ranged from 1 to 4 different products (average 1.0 product per person) for energy supplements, and from 1 to 2 different products (average $1 \cdot 0$ product per person) for weight-loss products.

\section{Types of supplements}

In terms of the types of supplements used, amino acid and protein supplements were most commonly used. Overall, $51.5 \%$ of supplement users used amino acid and protein products, followed by multivitamin or herb compounds (14.9\%) and carbohydrates and sugars (11.9\%). Overall, $40.0 \%$ of all supplement users used a supplement containing caffeine $(11.7 \%$ of all study participants) and $12.2 \%$ of supplement users took a product containing creatine $(3.6 \%$ of all study participants), including $4.1 \%$ who used a pure creatine monohydrate product.

Table 1 and Fig. 1 show the distribution of supplement types reported within the three categories of supplements investigated. Users of bodybuilding supplements most commonly used amino acid and protein supplements, typically taken as bars or powder $(90 \cdot 1 \%$ of all bodybuilding supplement users used these products). Multivitamin and herb compounds marketed to aid bodybuilding were also commonly used as a bodybuilding supplement (9.3\%), followed by products predominantly containing creatine monohydrate (8.5\%) and other products $(2 \cdot 8 \%)$. Besides creatine, multivitamin and herb products marketed for bodybuilding also commonly contained caffeine (24.0\% of such products).

Users of energy supplements most commonly used products that contained stimulants $(54.6 \%$ of all energy supplement users), almost always including caffeine. Users of energy supplements also often reported using amino acid and protein products $(21.2 \%)$, as well as 
Table 1 Subgroups of supplements used by used by current and ex-serving Australian Defence Force personnel $(n 14032)$ who deployed to the Middle East between 2001 and 2009

\begin{tabular}{|c|c|c|c|c|c|c|}
\hline & \multicolumn{2}{|c|}{ Total } & \multicolumn{2}{|c|}{ Contains creatine } & \multicolumn{2}{|c|}{ Contains caffeine } \\
\hline & $n$ & $\%$ & $n$ & $\%$ & $n$ & $\%$ \\
\hline \multicolumn{7}{|l|}{ Bodybuilding supplements } \\
\hline Amino acids/protein products & 1702 & $90 \cdot 1$ & 86 & $5 \cdot 1$ & 17 & 1.0 \\
\hline Multivitamin/herb compound & 175 & 9.3 & 72 & $41 \cdot 1$ & 42 & 24.0 \\
\hline Carbohydrates and sugars & 0 & 0.0 & & & & \\
\hline Stimulants & 0 & 0.0 & & & & \\
\hline Creatine monohydrate & 160 & 8.5 & 160 & $100 \cdot 0$ & 0 & 0.0 \\
\hline Other (non-prescription) & 9 & 0.5 & 0 & 0.0 & 0 & 0.0 \\
\hline Other (prescription medicine) & 0 & 0.0 & & & & \\
\hline Total users of bodybuilding supplements* & 1890 & $100 \cdot 0$ & 307 & $16 \cdot 2$ & 59 & 3.1 \\
\hline \multicolumn{7}{|l|}{ Energy supplements } \\
\hline Amino acids/protein products & 568 & $21 \cdot 2$ & 201 & $35 \cdot 4$ & 19 & $3 \cdot 3$ \\
\hline Multivitamin/herb compound & 505 & $18 \cdot 9$ & 0 & 0.0 & 1 & 0.2 \\
\hline Carbohydrates and sugars & 249 & 9.3 & 0 & 0.0 & 7 & $2 \cdot 8$ \\
\hline Stimulants & 1460 & $54 \cdot 6$ & 1 & 0.1 & 1442 & 98.8 \\
\hline Creatine monohydrate & 0 & 0.0 & & & & \\
\hline Other (non-prescription) & 0 & 0.0 & & & & \\
\hline Other (prescription medicine) & 0 & 0.0 & & & & \\
\hline Total users of energy supplements* & 2676 & $100 \cdot 0$ & 202 & 7.5 & 1463 & 54.7 \\
\hline \multicolumn{7}{|l|}{ Weight-loss supplements } \\
\hline Amino acids/protein products & 386 & 47.5 & 3 & 0.8 & 13 & 3.4 \\
\hline Multivitamin/herb compound & 99 & $12 \cdot 2$ & 0 & 0.0 & 18 & $18 \cdot 2$ \\
\hline Carbohydrates and sugars & 223 & $27 \cdot 4$ & 0 & 0.0 & 0 & 0.0 \\
\hline Stimulants & 78 & $9 \cdot 6$ & 0 & 0.0 & 76 & 97.4 \\
\hline Creatine monohydrate & 0 & 0.0 & & & & \\
\hline Other (non-prescription) & 7 & 0.9 & 0 & 0.0 & 0 & 0.0 \\
\hline Other (prescription medicine) & 47 & $5 \cdot 8$ & 0 & 0.0 & 0 & 0.0 \\
\hline Total users of weight-loss supplements* & 813 & $100 \cdot 0$ & 3 & 0.4 & 105 & $12 \cdot 9$ \\
\hline
\end{tabular}

${ }^{*}$ Total number of Australian Defence Force personnel in these categories do not equal to the sum of column responses because participants may have used more than one type of bodybuilding/energy/weight-loss supplement.

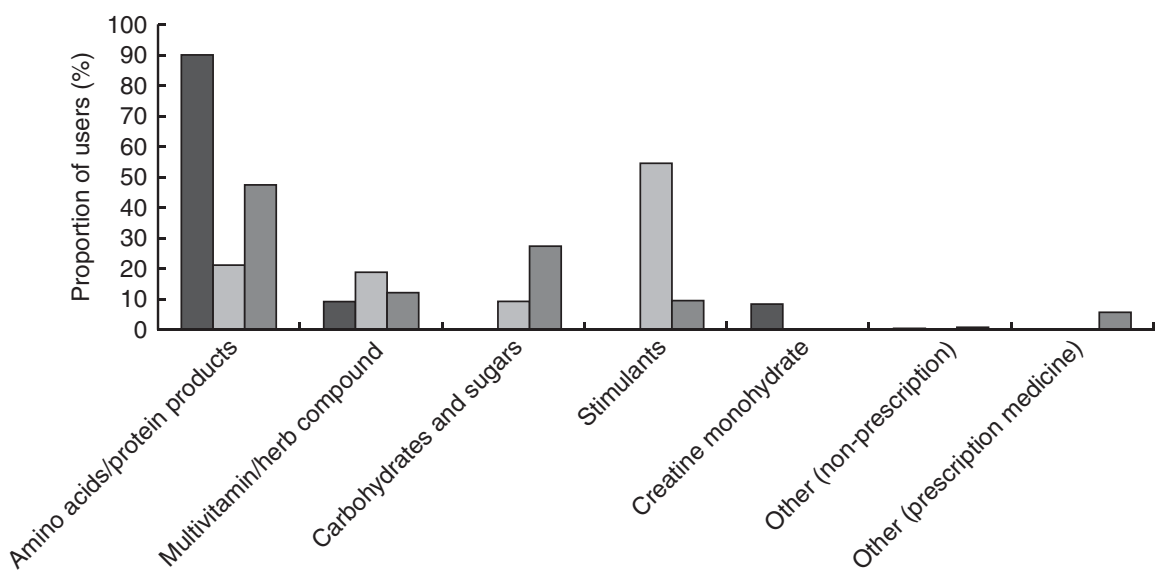

Fig. 1 Subgroups of supplements ( $\square$, bodybuilding supplements; $\square$, energy supplements; $\square$, weight-loss supplements) used by current and ex-serving Australian Defence Force personnel ( $n$ 14 032) who deployed to the Middle East between 2001 and 2009

multivitamin and herb products (18.9\%), but less often (9.3\%) products that predominantly contained carbohydrates and sugars. Users of weight-loss supplements most often used products that supplied protein and amino acids (47.5\%), carbohydrates and sugars (27.4\%), or multivitamin and herb compounds marketed to support weight loss $(12.2 \%)$. Stimulants (9.6\%), mainly containing caffeine ( $97.4 \%$ of such products), were also used as weight- loss supplements, while a small proportion of weight-loss supplement users (5.8\%) reported using prescription medicines to support weight loss.

\section{Factors associated with supplement use}

Men were more likely than women to use bodybuilding and energy supplements, while women were more likely to use weight-loss supplements. There was a clear 
age-related pattern of use, particularly for bodybuilding and energy supplements, with around a third of the youngest participants (aged 18-29 years) using such supplements, compared with less than $15 \%$ of the oldest ( $\geq 40$ years of age) study participants (all $P<0.001$; Table 2).

Army personnel were more likely to use of bodybuilding and energy supplements (about 25\% for both types of supplements) compared with Navy and Air Force personnel (12.2-24.0\%), while use of weight-loss supplements was somewhat more common in Navy personnel (9.2\%) compared with Army and Air Force ( 8.2 and $5.0 \%$, respectively). Use of supplements (any type) was generally highest among personnel in lower ranks, those deployed in active regular service and in combat positions (Table 2).

There was some evidence of an association between supplement use and other lifestyle factors. Current smokers were more likely to use energy and weight-loss supplements than never smokers, although differences between these groups were small (Table 2). Participants with a high intake of caffeine-containing drinks ( $\geq 6 \mathrm{cups} / \mathrm{d}$ ) were more likely to use energy and weight-loss supplements compared with persons who did not consume caffeine-containing drinks, while bodybuilding supplements were less frequently used by participants with moderate (3-5 cups/d) intake levels of caffeine-containing drinks compared with respondents who did not consume such drinks (Table 2).

\section{Health status}

In terms of recent symptoms reported by study participants, there were consistent patterns within each of the three categories of supplements (Table 3). Participants who used bodybuilding supplements reported less frequently than non-users that they suffered from a range of health problems including headaches, sleeping difficulties, flatulence, diarrhoea and indigestion, whereas such problems were more common among users of energy supplements and weight-loss supplements compared with non-users (Table 3). Multivariable modelling showed that these patterns were independent of the general demographic and job characteristics associated with supplement use, as identified in Table 2 .

Major depressive syndrome was more common in users $v$. non-users of energy supplements (4.2 v. 3.4\%) and weight-loss supplements ( 6.3 v. 3.4\%), but did not differ between users and non-users of bodybuilding supplements after adjustment for confounders (Table 3). Also, in terms of summary measures of physical and mental health (using the SF-12 assessment tool), physical health scores were lower on average for users of weight-loss supplements compared with non-users, but physical health was better in users compared with non-users of bodybuilding supplements (Table 3). Mental health summary scores were lower in users of energy and weight-loss supplements compared with non-users. The frequency of supplement use among users was lower for bodybuilding supplements and higher for energy supplements if the participant reported recent health symptoms; there was no such pattern for weight-loss supplements (detailed results not shown).

\section{Discussion}

Our findings show that bodybuilding, energy and weightloss supplements are commonly used by Australian military personnel who have served in the Middle East: about one in three persons reported using at least one of these types of supplements, with one in five persons using a supplement at least once weekly. This level of supplement use appears to be higher than that in the general Australian population. National survey data showed that $19 \%$ of Australian males aged 19-30 years, and 25\% of women in the same age group, use dietary supplements ${ }^{(1)}$, although specific national data on the types of supplements assessed in our study are not available for direct comparisons. We did not ask participants to report their reasons for dietary supplement use, but data from British Army soldiers suggest that general improvement of physical performance, and preparation prior to and recovery after training or physical activity may be the main motivating factors for choosing to use dietary supplements among military personnel ${ }^{(18)}$. US data indicate that energy drinks tend to be used by Army personnel to boost energy and enhance mental alertness ${ }^{(28)}$.

Compared with other military populations, supplement use was not as common in our study of Australian military personnel as in similar groups in other countries. A large survey of more than 16000 US military personnel in 2005 indicated that $25 \%$ used bodybuilding supplements (compared with $17 \%$ in our study) and $21 \%$ used weight-loss supplements (compared with only $7 \%$ in our study), while use of energy supplements could not be compared directly between the two studies ${ }^{(29)}$. Very similar to our observations, use of bodybuilding supplements was more common in US Army than Navy and Air Force personnel, and more common in younger than older persons, in men, and in nonsmokers compared with smokers ${ }^{(29)}$. Results from the US Millennium Cohort Study also indicated a higher overall use of supplements in US compared with Australian military personnel, with $47 \%$ of US military personnel reporting use of at least one type of bodybuilding, energy or weight-loss supplement (compared with $32 \%$ in our study). In particular, the use of energy supplements (38\%) and weight-loss supplements (19\%) was much higher in US compared with Australian military personnel ${ }^{(30)}$. The level of dietary supplement use in our study participants appears more similar to the level of use reported by British than US military personnel. In a survey of UK-based soldiers in training, 38\% reported current use of supplements, most commonly protein supplements and energy drinks ${ }^{(18)}$, which is comparable to the level of use reported in our study. 
Table 2 Associations between general demographic, service and lifestyle factors and use of dietary supplements by current and ex-serving Australian Defence Force personnel ( $n$ 14 032) who deployed to the Middle East between 2001 and 2009

\begin{tabular}{|c|c|c|c|c|c|c|c|c|c|c|c|c|c|c|c|}
\hline & \multicolumn{5}{|c|}{ Bodybuilding supplement use } & \multicolumn{5}{|c|}{ Energy supplement use } & \multicolumn{5}{|c|}{ Weight-loss supplement use } \\
\hline & Total $^{*}$ & $\%$ User† & AOR $\ddagger$ & $95 \% \mathrm{Cl}$ & $P$ & Total $^{*}$ & $\%$ User† & AOR§ & $95 \% \mathrm{Cl}$ & $P$ & Total $^{*}$ & $\%$ User† & AOR $\|$ & $95 \% \mathrm{Cl}$ & $P$ \\
\hline Overall & 13308 & $17 \cdot 5$ & & - & - & 13305 & $24 \cdot 5$ & & - & - & 13290 & $7 \cdot 6$ & & - & - \\
\hline \multicolumn{16}{|l|}{ Sex } \\
\hline Male & 11667 & $19 \cdot 0$ & 3.67 & $3.03,4.45$ & $<0.001$ & 11665 & $25 \cdot 0$ & 1.23 & $1.09,1.39$ & 0.001 & 11646 & $7 \cdot 0$ & 0.51 & $0.43,0.59$ & $<0.001$ \\
\hline Female & 1641 & $6 \cdot 3$ & & Ref. & & 1640 & $20 \cdot 7$ & & Ref. & & 1644 & $12 \cdot 0$ & & Ref. & - \\
\hline \multicolumn{16}{|l|}{ Age group (years) } \\
\hline $18-29$ & 3002 & 34.6 & 7.65 & $6.67,8.76$ & $<0.001$ & 2995 & $36 \cdot 4$ & 2.63 & $2 \cdot 37,2.92$ & $<0.001$ & 2997 & $9 \cdot 6$ & 1.41 & $1.20,1.67$ & $<0.001$ \\
\hline $30-39$ & 5385 & $17 \cdot 2$ & 3.29 & $2.91,3.72$ & $<0.001$ & 5385 & $25 \cdot 6$ & 1.86 & $1.70,2.04$ & $<0.001$ & 5377 & $7 \cdot 8$ & $1 \cdot 18$ & $1.03,1.36$ & 0.02 \\
\hline$\geq 40$ & 4921 & 5.8 & & Ref. & - & 4925 & 14.7 & & Ref. & & 4916 & $5 \cdot 8$ & & Ref. & - \\
\hline \multicolumn{16}{|l|}{ Service } \\
\hline Army & 6214 & $22 \cdot 3$ & 1.27 & $1.14,1.42$ & $<0.001$ & 6212 & $27 \cdot 3$ & $1 \cdot 12$ & $1.03,1.23$ & 0.01 & 6211 & 8.2 & 1.51 & $1.29,1.75$ & $<0.001$ \\
\hline Navy & 2987 & 13.8 & 0.80 & $0.68,0.93$ & 0.004 & 2985 & 24.0 & 0.98 & $0.87,1.10$ & 0.69 & 2981 & 9.2 & 1.57 & $1.30,1.88$ & $<0.001$ \\
\hline Air Force & 4107 & $12 \cdot 2$ & & Ref. & & 4108 & $19 \cdot 7$ & & Ref. & & 4098 & $5 \cdot 0$ & & Ref. & - \\
\hline \multicolumn{16}{|l|}{ Rank } \\
\hline Commissioned officer & 3985 & $11 \cdot 1$ & & Ref. & - & 3981 & $16 \cdot 7$ & & Ref. & - & 3972 & 4.8 & & Ref. & - \\
\hline Non-commissioned officer & 7881 & $17 \cdot 1$ & 1.34 & $1.21,1.48$ & $<0.001$ & 7886 & $24 \cdot 8$ & 1.40 & $1.28,1.52$ & $<0.001$ & 7879 & 8.4 & 1.65 & $1.44,1.89$ & $<0.001$ \\
\hline Lower ranks & 1442 & $29 \cdot 1$ & 1.39 & $1.19,1.63$ & $<0.001$ & 1438 & 35.5 & 1.59 & $1.38,1.83$ & $<0.001$ & 1439 & 8.9 & 1.34 & $1.06,1.68$ & 0.01 \\
\hline \multicolumn{16}{|l|}{ Service status } \\
\hline Active regular & 9583 & 18.5 & 1.39 & $1 \cdot 10,1 \cdot 76$ & 0.006 & 9581 & 24.6 & 0.85 & $0.72,1.02$ & 0.08 & 9574 & 8.0 & 1.31 & $0.97,1.76$ & 0.08 \\
\hline Active reserve & 1613 & 14.5 & 1.32 & $1.01,1.76$ & 0.04 & 1612 & $22 \cdot 3$ & 0.94 & $0.77,1.15$ & 0.54 & 1605 & $7 \cdot 1$ & 1.21 & $0.87,1.69$ & 0.26 \\
\hline Inactive reserve & 1318 & $18 \cdot 0$ & 1.31 & $1.01,1.71$ & 0.05 & 1321 & 23.6 & 0.82 & $0.66,1.00$ & 0.05 & 1319 & 6.5 & 1.06 & $0.75,1.50$ & 0.76 \\
\hline Ex-serving & 794 & $14 \cdot 2$ & & Ref. & - & 791 & $27 \cdot 7$ & & Ref. & - & 792 & $6 \cdot 9$ & & Ref. & - \\
\hline \multicolumn{16}{|l|}{ Main role on deployment } \\
\hline Combat & 3739 & $25 \cdot 7$ & 1.84 & $1 \cdot 62,2 \cdot 10$ & $<0.001$ & 3736 & 31.5 & 1.31 & $1 \cdot 18,1.46$ & $<0.001$ & 3731 & 9.6 & 1.53 & $1.29,1.82$ & $<0.001$ \\
\hline Combat support & 2384 & 14.5 & 1.22 & $1.06,1.40$ & 0.007 & 2381 & 19.6 & 0.85 & $0.75,0.95$ & 0.005 & 2383 & $6 \cdot 2$ & 1.04 & $0.86,1.25$ & 0.69 \\
\hline Medical/welfare & 495 & $12 \cdot 4$ & 1.73 & $1 \cdot 33,2.25$ & $<0.001$ & 495 & $16 \cdot 6$ & 0.89 & $0.72,1.12$ & 0.32 & 494 & $7 \cdot 3$ & 1.22 & $0.89,1.67$ & 0.22 \\
\hline Air crew & 709 & $9 \cdot 0$ & 0.89 & $0.71,1.13$ & 0.34 & 709 & 18.7 & 0.98 & $0.83,1.17$ & 0.85 & 708 & 3.7 & 0.87 & $0.63,1.20$ & 0.39 \\
\hline Maritime operations & 304 & $10 \cdot 1$ & $1 \cdot 17$ & $0.80,1.73$ & 0.42 & 304 & $20 \cdot 3$ & 0.93 & $0.70,1.24$ & 0.61 & 304 & $8 \cdot 3$ & 1.20 & $0.79,1.81$ & 0.39 \\
\hline Logistics & 2412 & 13.5 & & Ref. & - & 2419 & 23.5 & & Ref. & - & 2415 & $6 \cdot 2$ & & Ref. & - \\
\hline Administration & 228 & 8.2 & 0.92 & $0.62,1.36$ & 0.66 & 227 & $17 \cdot 3$ & 0.78 & $0.59,1.04$ & 0.09 & 228 & $8 . \overline{3}$ & 1.11 & $0.76,1.62$ & 0.6 \\
\hline Other roles & 1296 & 11.4 & 1.44 & $1.20,1.72$ & $<0.001$ & 1297 & $17 \cdot 9$ & 1.00 & $0.87,1.16$ & 0.96 & 1294 & $5 \cdot 8$ & $1 \cdot 16$ & $0.92,1.47$ & 0.21 \\
\hline \multicolumn{16}{|l|}{ Smoking history } \\
\hline Current & 3535 & 17.4 & 0.81 & $0.73,0.90$ & $<0.001$ & 3534 & $28 \cdot 6$ & 1.17 & $1.07,1.27$ & $<0.001$ & 3536 & 8.5 & $1 \cdot 14$ & $0.97,1.34$ & 0.1 \\
\hline Ex-smoker & 2345 & $15 \cdot 0$ & 1.12 & $0.98,1.27$ & 0.09 & 2345 & $20 \cdot 8$ & 0.97 & $0.87,1.08$ & 0.54 & 2341 & $7 \cdot 3$ & 1.11 & $0.96,1.28$ & 0.16 \\
\hline Never smoked & 7154 & 18.5 & & Ref. & - & 7152 & 23.6 & & Ref. & & 7141 & $7 \cdot 2$ & & Ref. & - \\
\hline \multicolumn{16}{|c|}{ Intake of caffeine-containing drinks } \\
\hline None & 1529 & 23.0 & & Ref. & & 1528 & 20.7 & & Ref. & & 1526 & 7.9 & & Ref. & - \\
\hline $1-2 / d$ & 6374 & $20 \cdot 1$ & 0.99 & $0.86,1 \cdot 13$ & 0.85 & 6372 & 26.5 & 1.62 & $1.42,1.86$ & $<0.001$ & 6361 & 7.5 & 1.05 & $0.87,1.27$ & 0.61 \\
\hline $3-5 / d$ & 4557 & $12 \cdot 7$ & 0.77 & $0.67,0.90$ & 0.001 & 4557 & $22 \cdot 6$ & 1.63 & $1.41,1.88$ & $<0.001$ & 4558 & $7 \cdot 1$ & $1 \cdot 11$ & $0.91,1.37$ & 0.3 \\
\hline$\geq 6 / d$ & 813 & 13.8 & 0.90 & $0.71,1.13$ & 0.34 & 814 & $26 \cdot 2$ & 1.83 & $1.50,2.22$ & $<0.001$ & 812 & $10 \cdot 1$ & 1.49 & $1.13,1.95$ & 0.004 \\
\hline
\end{tabular}

AOR, adjusted odds ratio; ref., reference category.

"Unweighted totals; totals may not add up due to missing responses.

†Percentages weighted for non-response; percentages may not sum to 100 due to rounding

Adjusted binary logistic regression models include all demographic, service and lifestyle variables listed in the table.

$\S$ Adjusted binary logistic regression models include the variable of interest adjusted for the confounding effects of gender, age group, service, rank, smoking history at survey completion and main role on deployment.

$\|$ Adjusted binary logistic regression models include the variable of interest adjusted for the confounding effects of gender, age group, service, rank, caffeine use at survey completion and main role on deployment. 
Table 3 Associations between physical and mental health and use of dietary supplements by current and ex-serving Australian Defence Force personnel ( $n$ 14 032 ) who deployed to the Middle East between 2001 and 2009

\begin{tabular}{|c|c|c|c|c|c|c|c|c|c|c|c|c|c|c|c|}
\hline & \multicolumn{5}{|c|}{ Bodybuilding supplement use } & \multicolumn{5}{|c|}{ Energy supplement use } & \multicolumn{5}{|c|}{ Weight-loss supplement use } \\
\hline & $\begin{array}{l}\text { Users } \\
(n 2169)\end{array}$ & $\begin{array}{l}\text { Non-users } \\
(n 11029)\end{array}$ & $\mathrm{AOR}^{*}$ & $95 \% \mathrm{Cl}$ & $P$ & $\begin{array}{l}\text { Users } \\
\text { (n 3068) }\end{array}$ & $\begin{array}{l}\text { Non-users } \\
(n 10128)\end{array}$ & $\mathrm{AOR}^{*}$ & $95 \% \mathrm{Cl}$ & $P$ & $\begin{array}{l}\text { Users } \\
(n 980)\end{array}$ & $\begin{array}{l}\text { Non-users } \\
(n \text { 12201) }\end{array}$ & $\mathrm{AOR}^{\star}$ & $95 \% \mathrm{Cl}$ & $P$ \\
\hline \multicolumn{16}{|l|}{ Recent health symptoms (\%) } \\
\hline Headaches & $40 \cdot 5$ & 49.6 & 0.80 & $0.73,0.87$ & $<0.001$ & $51 \cdot 8$ & $46 \cdot 7$ & 1.32 & $1.23,1.43$ & $<0.001$ & 53.2 & 47.5 & $1 \cdot 18$ & $1.05,1.33$ & 0.006 \\
\hline Sleeping difficulties & 53.7 & $56 \cdot 0$ & $1 \cdot 10$ & $1.00,1.20$ & 0.05 & 61.0 & 53.9 & 1.46 & $1.35,1.58$ & $<0.001$ & $67 \cdot 2$ & 54.7 & 1.73 & $1.53,1.96$ & $<0.001$ \\
\hline Constipation & 7.7 & 10.5 & 1.02 & $0.86,1.21$ & 0.83 & 10.5 & 9.8 & 1.30 & $1.14,1.47$ & $<0.001$ & 13.1 & 9.7 & 1.37 & $1.14,1.63$ & $<0.001$ \\
\hline Flatulence or burping & 23.9 & 30.7 & 0.87 & $0.79,0.97$ & 0.01 & 31.5 & $28 \cdot 8$ & 1.35 & $1.24,1.47$ & $<0.001$ & 33.3 & 29.1 & 1.26 & $1.11,1.43$ & $<0.001$ \\
\hline Stomach cramps & 12.6 & 14.0 & 1.01 & $0.88,1.16$ & 0.88 & 15.9 & 13.1 & 1.37 & $1.23,1.53$ & $<0.001$ & 18.4 & 13.4 & 1.37 & $1.17,1.61$ & $<0.001$ \\
\hline Diarrhoea & $17 \cdot 9$ & $20 \cdot 8$ & 0.88 & $0.78,0.99$ & 0.04 & 23.0 & $19 \cdot 4$ & 1.31 & $1.20,1.44$ & $<0.001$ & $25 \cdot 6$ & 19.9 & 1.39 & $1.22,1.59$ & $<0.001$ \\
\hline Indigestion & $13 \cdot 3$ & $18 \cdot 6$ & 0.85 & $0.74,0.97$ & 0.01 & $19 \cdot 0$ & $17 \cdot 3$ & 1.34 & $1.21,1.48$ & $<0.001$ & $21 \cdot 2$ & 17.4 & 1.30 & $1.12,1.51$ & $<0.001$ \\
\hline Nausea & 6.0 & 7.6 & 0.91 & $0.75,1.10$ & 0.34 & 8.9 & 6.8 & 1.48 & $1.28,1.71$ & $<0.001$ & 9.5 & $7 \cdot 1$ & 1.17 & $0.95,1.44$ & 0.14 \\
\hline Vomiting & $3 \cdot 2$ & 3.6 & 0.92 & $0.71,1.19$ & 0.29 & 4.2 & $3 \cdot 2$ & 1.39 & $1.14,1.70$ & 0.001 & 4.8 & 3.4 & 1.23 & $0.92,1.64$ & 0.17 \\
\hline $\begin{array}{l}\text { Total number of health } \\
\text { symptoms, meant }\end{array}$ & 1.8 & $2 \cdot 1$ & 0.95 & $0.90,1.01$ & 0.0824 & $2 \cdot 2$ & 1.9 & 1.20 & $1 \cdot 16,1.25$ & $<0.001$ & $2 \cdot 4$ & $2 \cdot 0$ & $1 \cdot 19$ & $1 \cdot 12,1 \cdot 27$ & $<0.001$ \\
\hline $\begin{array}{l}\text { SD } \\
\text { Health status }\end{array}$ & 1.8 & 1.9 & & & & $2 \cdot 0$ & 1.9 & & & & $2 \cdot 1$ & 1.9 & & & \\
\hline $\begin{array}{l}\text { Physical health, mean } \ddagger \\
\text { SD }\end{array}$ & $\begin{array}{r}53 \cdot 1 \\
7 \cdot 4\end{array}$ & $\begin{array}{r}51 \cdot 2 \\
8 \cdot 4\end{array}$ & $1 \cdot 1$ & $0.8,1.5$ & $<0.001$ & $\begin{array}{r}51 \cdot 6 \\
8.4\end{array}$ & $\begin{array}{r}51 \cdot 5 \\
8.2\end{array}$ & -0.3 & $-0.7,-0.01$ & 0.05 & $\begin{array}{r}49 \cdot 9 \\
9.2\end{array}$ & $\begin{array}{r}51 \cdot 7 \\
8 \cdot 2\end{array}$ & $-1 \cdot 6$ & $-2 \cdot 2,-1 \cdot 1$ & $<0.001$ \\
\hline $\begin{array}{l}\text { Mental health, mean§ } \\
\text { SD }\end{array}$ & $\begin{array}{l}49 \cdot 7 \\
10 \cdot 0\end{array}$ & $\begin{array}{l}49 \cdot 3 \\
10 \cdot 2\end{array}$ & -0.01 & $-0.5,0.5$ & 0.96 & $\begin{array}{l}48 \cdot 1 \\
10 \cdot 7\end{array}$ & $\begin{array}{l}49.7 \\
10.0\end{array}$ & $-1 \cdot 7$ & $-2 \cdot 1,-1 \cdot 3$ & $<0.001$ & $\begin{array}{l}46 \cdot 9 \\
10 \cdot 9\end{array}$ & $\begin{array}{l}49.5 \\
10.1\end{array}$ & $-2 \cdot 2$ & $-2 \cdot 9,-1 \cdot 6$ & $<0.001$ \\
\hline $\begin{array}{l}\text { Major depressive } \\
\text { syndrome }(\%)\end{array}$ & 2.4 & 3.9 & 0.79 & $0.57,1.10$ & 0.16 & 4.2 & 3.4 & 1.33 & $1.06,1.66$ & 0.01 & 6.3 & 3.4 & 1.91 & $1.45,2.53$ & $<0.001$ \\
\hline
\end{tabular}

AOR, adjusted odds ratio.

*Binary logistic regression models comparing users $v$. non-users, adjusting for sex, age group, service, rank, service status, main role during most recent deployment, current smoking status (bodybuilding and energy supplements only) and consumption of caffeine-containing drinks (bodybuilding and weight-loss supplements only).

tUnweighted means and SD.

fUnweighted means and SD of Short Form-12 Health Survey Physical Component Score.

§Unweighted means and SD of Short Form-12 Health Survey Mental Component Score. 
Our data indicated quite clear patterns of personal characteristics that were associated with use of supplements. Bodybuilding supplements tended to be used more often by individuals in active service, with better health behaviours and of better self-reported health (with a lower level of supplement use if the person reported health symptoms). In contrast, use of energy and weight-loss supplements was not associated with service status (active or inactive), and these supplements were more commonly used by participants with poorer health behaviours and with poorer physical and mental health. However, differences in mental and physical health between groups were generally very small and the clinical significance of these differences is uncertain.

This patterning of demographic characteristics with supplement type is very similar to that observed in other studies. For example, in the US Millennium Cohort Study, users of bodybuilding supplements were generally younger, more physically active and healthier, while users of energy and weight-loss supplements tended to be less physically active and to have poorer health indicators ${ }^{(30)}$. Similarly in British Army soldiers in training, overall use of dietary supplements was associated with higher levels of physical activity, although supplement use was higher in smokers compared with non-smokers ${ }^{(18)}$; we could not directly compare data for subgroups of supplements.

Associations with recent health symptoms and summary measures of health status also showed fairly consistent patterning, in that users of bodybuilding supplements had better physical and mental health, in contrast to users of energy and weight-loss supplements. This pattern of associations is very similar to that reported for US Army staff ${ }^{(30)}$, including that of a large survey of US Armed Forces which found that multivitamin/minerals and protein/amino acid supplements were associated with better general health, eating habits and fitness levels ${ }^{(31)}$. Recent US data also indicated that the use of a combination of dietary supplement products is most commonly associated with sideeffects $^{(32,33)}$. However, because details of health symptoms in our study participants were not specifically reported in the context of dietary supplement use, we cannot draw any conclusions about side-effects from our data.

We found that the prevalence of major depressive syndrome was twice as high in users of weight-loss supplements than among non-users of weight-loss supplements. Due to the cross-sectional nature of our data collection we are unable to ascertain which factors are causes and which factors are consequences in these associations, but this observation raises the possibility that the increasing prevalence of overweight and obesity among military populations ${ }^{(7,8)}$ may have impacts on mental as well as physical health in this group. Measures of overweight or obesity were unfortunately not available for our study participants.

We were particularly interested in the use of supplements that contain caffeine. Military personnel may have higher levels of caffeine intake than the general population because caffeine alleviates the adverse cognitive consequences of sleep deprivation (e.g. due to long work shifts) and it enhances physical performance ${ }^{(13)}$. However, there is also concern about possible side-effects of high caffeine intake ${ }^{(34,35)}$, such as disturbed sleep patterns ${ }^{(14)}$ as a result of use of caffeinated products during overnight periods of sustained wakefulness.

In our study, sleeping difficulties were higher in users of energy supplements ( $55 \%$ of which contained caffeine) and weight-loss supplements (13\% of which contained caffeine) compared with non-users of such supplements. However, because of the cross-sectional nature of our data, and because we were unable to quantify caffeine intake, it is not possible to draw any firm conclusions about the role of caffeine-containing supplements in these health symptoms. Nevertheless, our data show that use of caffeine-containing supplements was common $(11.7 \%$ of all participants used these), which adds to the caffeine intake obtained from caffeine-containing drinks ( $40 \%$ of respondents consumed three or more caffeine drinks daily), raising the possibility of very high caffeine intake levels in some persons. Observations from US military personnel have also indicated that use of caffeinecontaining energy drinks is very common, particularly among young males, and that sleeping difficulties may be associated with this ${ }^{(28)}$. Our data did not facilitate calculation of total caffeine intake for the study participants. However, it is known that the caffeine content of supplements is highly variable and poorly listed in product information $^{(34)}$, and thus difficult to quantify. A more detailed study on levels of caffeine intake in the Australian military, or monitoring of levels of intake at an individual level, and its impact on the health of serving personnel may therefore be warranted.

Our study is the first to report supplement use in Australian military personnel, and a major strength of the study is its large number of participants and comprehensive assessment of physical and mental health, as well as demographic and lifestyle factors. Other strengths include the fact that the response rate compared favourably with other, similar studies (as discussed in detail in the MEAO Survey report ${ }^{(25)}$ ) and the results were weighted for nonresponse to control for potential response bias. Furthermore, standard, validated instruments were used, which allows comparison with other military and civilian studies.

However, the study has some limitations that need to be considered when interpreting the results. The data on dietary supplement use were self-reported by the study participants and such self-reporting may be influenced by reporting biases ${ }^{(36)}$. It is a cross-sectional study and thus we were unable to ascertain whether health symptoms were a cause or a consequence of supplement use. Health status indicators were based on self-reported data, which may be affected by recall bias. However, these health data were collected as part of a larger health survey and not 
specifically in the context of a study of dietary supplements, thus it is very unlikely that misreporting (if any) caused a systematic bias in our present analyses. Full details on the frequency dose of supplements taken, and use of dietary supplements other than those in the categories reported here, were not ascertained in the MEAO Survey questionnaire. Thus, unfortunately, we cannot directly compare absolute amounts of supplement use (of any type) with other populations.

There is a variety of reasons why patterns of dietary supplement use may be different among military (and general) populations of different nations, for example due to different availability of supplements, diverse product ranges, different marketing practices, different regulatory laws, differences in dietary and related health habits, etc. One of the problems with comparisons between different studies is the differences in the definition of 'supplement user'. For example, we have chosen to focus our analyses on supplement users at any frequency of use, similar to others $^{(18,30)}$, while some different studies have focused on persons who use a dietary supplement at least once weekly ${ }^{(6,32)}$. The questionnaire items relating to dietary supplement use in the larger health questionnaire of the MEAO Survey, from which our data were extracted, were designed to focus on the intended use of supplements (bodybuilding, energy or weight loss). However, in our analyses we have also incorporated a more ingredientfocused categorisation (amino acids, multivitamins, etc.), to the best of our ability given the available data and resources. While direct comparisons of dietary supplement use in different nations will always have limitations due to the inherent differences in dietary supplement products available around the world, it would be very useful if an agreement could be reached over a standardised method of categorising these products, as well as the frequency of use that would characterise someone as a regular supplement user.

We were able to find product information for almost all supplements reported by the study participants, but a very small number of misclassifications may have occurred. We observed that products that may be quite similar in composition are sometimes marketed for divergent purposes of use (e.g. protein supplements are marketed as bodybuilding supplements as well as weight-loss supplements), and conversely there are products that fall into the same category (e.g. weight loss) but have very little overlap in terms of ingredients ${ }^{(37)}$. This makes it difficult to study health effects of specific supplement ingredients in detail, but at the same time this emphasises the need to monitor for possible side-effects of dietary supplements at an individual level, including among military personnel $^{(38)}$. General provision of information about dietary supplements ${ }^{(39)}$ would be prudent for military personnel. Military personnel are known to be healthier on average than members of the general population (the healthy soldier effect ${ }^{(40)}$ ), but our findings indicate that regardless of their better health, use of dietary supplements is very common among Australian military personnel. Our data may help those in charge of reviewing the health status of ADF personnel to identify priorities for further, more detailed investigations of supplement use by military personnel, and to review the potential risks associated with use of certain dietary supplements in this large population group. The recent banning of all DMAA (dimethylamylamine) containing supplements by the Australian Therapeutic Goods Administration illustrates the need for regulation to prevent avoidable risks to the health of military personnel and the population at large.

\section{Conclusion}

In conclusion, our study shows that bodybuilding and energy supplements are commonly used by ADF personnel who have served in the Middle East. Our data indicate that patterns of use are associated with employment and lifestyle factors, as well as health symptoms. Although we were unable to ascertain absolute amounts of intake of dietary supplements and ingredients, our findings may help identify subgroups of Australian military personnel who may be at risk of possible side-effects.

\section{Acknowledgements}

Acknowledgements: The authors thank the veterans who participated in the survey. Helpful comments on this manuscript by Lieutenant Colonel Peter Nasveld are gratefully acknowledged. Financial support: The MEAO Census Study was funded by the Australian Government Department of Defence. The authors used data from the MEAO Census Study during the course of their employment with The University of Queensland, School of Public Health. The authors received no funding from the Australian Government Department of Defence for this specific work. The opinions or assertions contained herein are the private views of the authors and are not to be construed as official, or representing the views of the Australian Defence Force or Department of Defence. The Department of Defence had no role in the design, analysis or writing of this article. Conflict of interest: None. Authorship: J.C.v.d.P. oversaw data extraction and analyses, and wrote the paper; J.K. supported extraction of product data, carried out statistical analyses and helped write the paper; A.B. extracted product data and helped write the paper; C.-W.L. conceptualised the idea and helped write the paper. All authors read and approved the final manuscript. Ethics of buman subject participation: Ethical approval for the present study was obtained from the Australian Department of Defence (protocol number LREP 14-010) and The University of Queensland (protocol number 2009001441) ethics committees. Participants of 
the MEAO Survey provided consent in writing or electronically, and all aspects of this research complied with the Declaration of Helsinki.

\section{References}

1. Australian Bureau of Statistics (2014) Australian Health Survey: Nutrition First Results - Foods and Nutrients, 2011-12. http://www.abs.gov.au/australianhealthsurvey? (accessed April 2016).

2. Hathcock JN (1997) Vitamins and minerals: efficacy and safety. Am J Clin Nutr 66, 427-437.

3. Jimenez-Flores R, Heick J, Davis SC et al. (2012) A comparison of the effects of a high carbohydrate vs. a higher protein milk supplement following simulated mountain skirmishes. Mil Med 177, 723-731.

4. Naclerio F \& Larumbe-Zabala E (2016) Effects of whey protein alone or as part of a multi-ingredient formulation on strength, fat-free mass, or lean body mass in resistancetrained individuals: a meta-analysis. Sports Med $\mathbf{4 6}$ 125-137.

5. Craig WJ, Mangels AR \& American Dietetic Association (2009) Position of the American Dietetic Association: vegetarian diets. J Am Diet Assoc 109, 1266-1282.

6. Lieberman HR, Stavinoha TB, McGraw SM et al. (2010) Use of dietary supplements among active-duty US Army soldiers. Am J Clin Nutr 92, 985-995.

7. Peake J, Gargett S, Waller M et al. (2012) The health and cost implications of high body mass index in Australian defence force personnel. BMC Public Health 12, 451.

8. Reyes-Guzman CM, Bray RM, Forman-Hoffman VL et al. (2015) Overweight and obesity trends among active duty military personnel: a 13-year perspective. Am J Prev Med 48, 145-153.

9. Jenkinson DM \& Harbert AJ (2008) Supplements and sports. Am Fam Physician 78, 1039-1046.

10. Bishop D (2010) Dietary supplements and team-sport performance. Sports Med 40, 995-1017.

11. Trexler ET \& Smith-Ryan AE (2015) Creatine and caffeine: considerations for concurrent supplementation. Int J Sport Nutr Exerc Metab 25, 607-623.

12. Spriet LL (2014) Exercise and sport performance with low doses of caffeine. Sports Med 44, Suppl. 2, S175-S184.

13. Lieberman HR, Stavinoha T, McGraw S et al. (2012) Caffeine use among active duty US Army soldiers. J Acad Nutr Diet 112, 902-912, 912.e1-e4.

14. Clark I \& Landolt HP (2016) Coffee, caffeine, and sleep: a systematic review of epidemiological studies and randomized controlled trials. Sleep Med Rev 31, 70-78.

15. Waits WM, Ganz MB, Schillreff T et al. (2014) Sleep and the use of energy products in a combat environment. US Army Med Dep J Oct-Dec issue, 22-28.

16. Burke J, Seda G, Allen D et al. (2007) A case of severe exercise-induced rhabdomyolysis associated with a weightloss dietary supplement. Mil Med 172, 656-658.

17. Manore MM (2012) Dietary supplements for improving body composition and reducing body weight: where is the evidence? Int J Sport Nutr Exerc Metab 22, 139-154.

18. Casey A, Hughes J, Izard RM et al. (2014) Supplement use by UK-based British Army soldiers in training. BrJ Nutr $\mathbf{1 1 2}$, $1175-1184$

19. Boos CJ, Simms P, Morris FR et al. (2011) The use of exercise and dietary supplements among British soldiers in Afghanistan. J R Army Med Corps 157, 229-232.

20. Austin KG, McLellan TM, Farina EK et al. (2016) Soldier use of dietary supplements, including protein and body building supplements, in a combat zone is different than use in garrison. Appl Physiol Nutr Metab 41, 88-95.

21. Boos CJ, Wheble GAC, Campbell MJ et al. (2010) Self-administration of exercise and dietary supplements in deployed British military personnel during Operation TELIC 13. J R Army Med Corps 156, 32-36.

22. Cassler NM, Sams R, Cripe PA et al. (2013) Patterns and perceptions of supplement use by US Marines deployed to Afghanistan. Mil Med 178, 659-664.

23. Austin K, Price L, McGraw S et al. (2014) Longitudinal trends of dietary supplement use by US Army soldiers differ from the US civilian population. FASEB J 28, 245-246.

24. Greenwood MRC \& Oria M (2008) Use of Dietary Supplements by Military Personnel. Washington, DC: National Academies Press.

25. Dobson A, Treloar S, Zheng WY et al. (2013) The Middle East Area of Operations (MEAO) Health Study: Census Study Report, vol. 1. Brisbane: The The University of Queensland, Centre for Military and Veterans' Health.

26. Ware J, Kosinski M \& Keller S (1996) A 12-Item Short-Form Health Survey: construction of scales and preliminary tests of reliability and validity. Med Care 34, 220-233.

27. Kroenke K, Spitzer RL \& Williams JBW (2001) The PHQ-9. J Gen Intern Med 16, 606-613.

28. Stephens MB, Attipoe S, Jones D et al. (2014) Energy drink and energy shot use in the military. Nutr Rev 72, 72-77.

29. Kao T-C, Deuster PA, Burnett D et al. (2012) Health behaviors associated with use of body building, weight loss, and performance enhancing supplements. Ann Epidemiol 22, 331-339.

30. Jacobson IG, Horton JL, Smith B et al. (2012) Bodybuilding, energy, and weight-loss supplements are associated with deployment and physical activity in US military personnel. Ann Epidemiol 22, 318-330.

31. Austin KG, McGraw SM \& Lieberman HR (2014) Multivitamin and protein supplement use is associated with positive mood states and health behaviors in US Military and Coast Guard personnel. J Clin Psychopharmacol 34, 595-601.

32. Knapik JJ, Trone DW, Austin KG et al. (2016) Prevalence, adverse events, and factors associated with dietary supplement and nutritional supplement use by US Navy and Marine Corps personnel. J Acad Nutr Diet 116, $1423-1442$.

33. Austin KG, Farina EK \& Lieberman HR (2016) Self-reported side-effects associated with use of dietary supplements in an armed forces population. Drug Test Anal 8, 287-295.

34. Cohen PA, Attipoe S, Travis J et al. (2013) Caffeine content of dietary supplements consumed on military bases. JAMA Intern Med 173, 592-594.

35. Wesensten NJ (2014) Legitimacy of concerns about caffeine and energy drink consumption. Nutr Rev 72, 78-86.

36. Sikkens JJ, van Eijsden M, Bonsel GJ et al. (2011) Validation of self-reported folic acid use in a multiethnic population: results of the Amsterdam Born Children and their Development study. Public Health Nutr 14, 2022-2028.

37. Geller AI, Shehab N, Weidle NJ et al. (2015) Emergency department visits for adverse events related to dietary supplements. N Engl J Med 373, 1531-1540.

38. Siano KA (2014) Renal failure in a soldier taking N.O.Xplode. J Am Board Fam Med 27, 565-569.

39. The Canadian Forces Health Services Group (2004) The Dietary Supplement Dilemma: Helpful or Harmful? http://publications.gc.ca/site/fra/9.835612/publication.html (accessed May 2016)

40. McLaughlin R, Nielsen L \& Waller M (2008) An evaluation of the effect of military service on mortality: quantifying the healthy soldier effect. Ann Epidemiol 18, 928-936. 